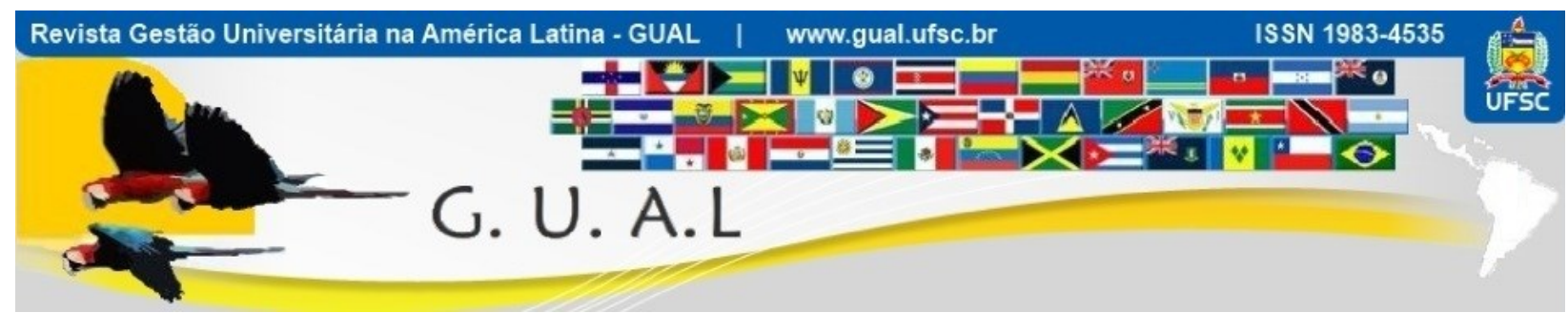

DOI: https://doi.org/10.5007/1983-4535.2021.e73528

\title{
MENSURAÇÃO DO GRAU DE RISCO NOS PROCESSOS LICITATÓRIOS DE UMA INSTITUIÇÃO FEDERAL DE ENSINO SUPERIOR
}

\section{MEASUREMENT OF RISK DEGREE IN THE BIDDING PROCESSES OF A FEDERAL INSTITUTION OF HIGHER EDUCATION}

Tatiane Duarte Dias Mohr, Mestre https://orcid.org/0000-0001-6704-6001 tatianemohr@utfpr.edu.br

Universidade Tecnológica Federal do Paraná | Divisão de Orçamento e Finanças do Câmpus Curitiba Curitiba | Paraná | Brasil

Abdinardo Moreira Barreto de Oliveira, Doutor https://orcid.org/0000-0002-9377-6267 abdinardom@utfpr.edu.br

Universidade Tecnológica Federal do Paraná | Departamento Acadêmico de Administração do Câmpus Pato Branco Pato Branco | Paraná | Brasil

Recebido em 04/maio/2020

Aprovado em 13/outubro/2020

Publicado em 01/janeiro/2021

Sistema de Avaliação: Double Blind Review

Esta obra está sob uma Licença Creative Commons Atribuição-Uso. 


\title{
RESUMO
}

Esta pesquisa teve como objetivo mensurar o grau de risco associado aos processos licitatórios realizados através de Pregões Eletrônicos. Para tal, foi realizado um estudo na Universidade Tecnológica Federal do Paraná. A metodologia utilizada foi uma pesquisa descritiva com abordagem quantitativa por meio de um questionário baseado em estudos anteriores e cujos constructos foram elaborados conforme os princípios da Economia dos Custos de Transação. Foi aplicada a análise fatorial para definir a ordem de relevância dos fatores que os participantes dos processos licitatórios consideram mais importantes no certame. A análise de Cluster possibilitou dividir os fornecedores em dois grupos: baixo (61\%) e alto risco (39\%). A ordem de relevância dos fatores encontrada traz informações que devem ser analisadas com cautela a fim de se criar procedimentos mais rigorosos na hora de elaborar editais, redigir contratos e aplicar punições por descumprimento de contratos.

Palavras-chave: Pregão Eletrônico. Nova Economia Institucional. Economia dos Custos de Transação.

\begin{abstract}
This research aimed to measure the degree of risk associated with bidding processes carried out through Electronic Auction. To this end, a study was carried out at the Federal University of Technology - Paraná. The methodology used was a descriptive research with a quantitative approach through a questionnaire based on previous studies and whose constructs were elaborated according to the principles of Transaction Cost Economics. Factor analysis was applied to define the order of relevance of the factors that participants in the bidding processes consider most important in the event. The Cluster analysis made it possible to divide suppliers into two groups: low $(61 \%)$ and high risk $(39 \%)$. The order of relevance of the factors found brings information that must be analyzed with caution in order to create more rigorous procedures when preparing public notices, writing contracts and applying penalties for noncompliance with contracts.
\end{abstract}

Keywords: Electronic Auction. New Institutional Economics. Economics of Transaction Costs. 


\section{INTRODUÇÃO}

Uma das formas de contratação que ganhou importância significativa ao longo dos últimos anos foi o Pregão. Com o advento do Pregão Eletrônico, a maior parte dos processos licitatórios passou a ser realizado recorrendo a essa modalidade e, consequentemente, grande parte do orçamento destinado aos órgãos públicos é utilizado para as contratações provenientes deste tipo de pregão. Posto isso, é indiscutível a importância dos processos licitatórios dentro da Administração Pública, especialmente o Pregão Eletrônico que visa proporcionar um processo de compra mais célere e transparente (PAZ, 2016). No entanto, é necessário pensar que todo esse processo envolve custos e riscos, tanto para quem está contratando como para quem está participando do certame. Sendo assim, faz-se necessário avaliar os riscos relacionados a este tipo de certame a fim de salvaguardar o erário público.

Sendo assim, com a finalidade de dar continuidade à discussão deste assunto no âmbito da Administração Pública, foi proposto medir o grau de riscos ao qual a Universidade Tecnológica Federal do Paraná (UTFPR) está exposta ao realizar contratações por meio de pregões eletrônicos a partir da visão de seus fornecedores e considerando a Economia dos Custos de Transação. Ademais, esta pesquisa foi baseada nos estudos de Faria (2009) e Santos (2010), a fim de verificar quais possíveis convergências ou divergências serão encontradas em relação aos estudos anteriores e também averiguar a influência da localização geográfica sobre os resultados.

\section{FUNDAMENTAÇÃO TEÓRICA}

\subsection{PREGÃO ELETRÔNICO}

O Decreto $\mathrm{n}^{\mathrm{o}}$ 5.450, de 31 de maio de 2005 (BRASIL, 2005) regulamentou a modalidade de licitação pregão na forma eletrônica no âmbito da União. "Este decreto instituiu que o Pregão Eletrônico deve ser modalidade preferencial, sendo obrigatório para a contratação de serviços e aquisição de bens considerados comuns" (ALVES-ANDRADE; GUARIDO FILHO; EBERLE, 2017, p. 245). Também de acordo com Paz, “o uso de meios eletrônicos possibilita maior transparência nas contratações realizadas pela Administração Pública” (2016, p. 19).

Por meio desta regulamentação, benefícios, como o uso de tecnologia da informação, foram acrescidos às circunstâncias encontradas neste tipo de certame (FARIA; OLIVEIRA, 2016). Além disso, o Pregão Eletrônico representa vantagens ligadas à ampliação das ofertas e 
à transparência do processo e deve ser usado sempre que as condições da licitação permitirem (PONTES; XAVIER, 2017).

Uma das grandes vantagens do pregão na forma eletrônica é que os participantes não precisam reunir-se em um local físico, pois todo o certame será realizado através da Rede Mundial de Computadores, a Internet. Este fato diminui custos e possibilita a participação de fornecedores de diversas regiões, deixando a disputa mais acirrada e, consequentemente, mais proveitosa para a Administração Pública. Cabe ratificar que a difusão deste tipo de processo é de extrema importância para os membros da Administração Pública, fornecedores e para os cidadãos, tendo em vista que a economia gerada, a celeridade, a transparência e outros aspectos são de interesse de toda a população (FARIA; OLIVEIRA, 2016).

\subsection{NOVA ECONOMIA INSTITUCIONAL E ECONOMIA DOS CUSTOS DE TRANSAÇÃO}

Oliver Williamsom ensina que a NEI nasce por volta dos anos 1960 depois de um decréscimo no estudo das economias institucionais no pós-guerra. Além disso, o autor conta que a Nova Economia Institucional tem como uma de suas partes aquilo que se convencionou chamar Economia dos Custos de Transação (ECT), que entende os custos para que um sistema econômico possa rodar como unidade básica de qualquer análise (WILLIAMSON, 1985). Citando Williamson, Ferreira e colaboradores explicam que custos de transação são definidos e distinguidos em custos ex-ante, relacionados ao preparo, negociação e salvaguarda de um acordo e "custos ex-post dos ajustamentos e adaptações quando a execução de um contrato é afetada por falhas, erros, omissões e alterações inesperada" (FERREIRA et al., 2005, p. 6).

A ECT, como mencionado, é uma parte da NEI e os autores lembram de que ela, a seu turno, é uma teoria que pretende estudar formas mais eficientes para que uma organização realize suas transações econômicas (FERREIRA et al., 2005); e Bueno diz que sua proposição fundamental "é que as instituições de uma sociedade se formam por meio de complexos processos de negociação entre indivíduos e grupos de indivíduos, de modo a reduzir os custos de transação" (BUENO, 2004, p. 778). Nesse sentido, seu objetivo é estudar o dispêndio das transações como determinantes para mudanças significativas na coordenação da produção de uma organização. Assim, diz Richetti e Santos, que "a nova economia institucional (NEI) [...] tem por objetivo o estudo do custo das transações como indutor dos modos alternativos de organização da produção, dentro de um arcabouço analítico institucional” (2000, p. 35). 
Através da ótica da economia dos custos de transação as organizações devem ser encaradas como arranjos alternativos ou como estruturas de governança que objetivam economizar em custos de transação (RICHETTI; SANTOS, 2000). Neste sentido, Williamson, considerado o principal percursor das ideias de Coase e o mais importante representante da ECT, procura relacionar as atividades organizacionais com a busca de respostas mais eficazes frente ao ambiente econômico, resultando na redução dos custos de transação (SIMIONI; PEREIRA, 2004).

Sendo assim, finalmente, cabe trazer à luz aquilo que alguns autores vão considerar como os principais aspectos da NEI e da ECT. Assim, esses aspectos (que serão explicados a seguir) compõem certa parte da análise da teoria e podem ser divididos em pressupostos comportamentais (Racionalidade Limitada e Oportunismo) e as dimensões relativas às transações (Especificidade de ativos, Frequência e Incerteza) (FERREIRA et al., 2005).

\subsubsection{Racionalidade limitada}

A racionalidade limitada aborda a questão do comportamento humano, esclarecendo que este é limitado em face da grande gama de informações que fazem parte de uma transação (MARAGNO; KALATZIS; PAULILLO, 2006). A origem para a existência dos custos de transação é o reconhecimento de que os agentes são racionais, mas de forma limitada, e possuem natureza oportunista. Em função da racionalidade limitada os contratos serão incompletos tendo em vista o alto grau de complexidade que há em prever e processar todos os eventos futuros que podem ocorrer na execução de um contrato. Sendo assim, não é possível medir ex-ante determinados fatores de uma transação (FARINA; AZEVEDO; SAES, 1997). A combinação da racionalidade limitada com a incerteza dificulta a definição e a distinção das probabilidades de ocorrência de fatos ou eventos que podem afetar a transação. Além disso, podem surgir problemas decorrentes da assimetria de informações criando um ambiente propício para práticas oportunistas, que estão relacionadas à manipulação da assimetria informacional visando o benefício próprio (MARAGNO; KALATZIS; PAULILLO, 2006).

Contudo, cabe entender que, mesmo de forma limitada, os indivíduos são racionais, e, portanto, buscam adaptações contratuais ex-post, a exemplo da inclusão de salvaguardas, na intenção de contornar as inevitáveis brechas presentes nos contratos. Sendo assim, em função 
da racionalidade limitada, todos os contratos são inevitavelmente incompletos dentro da ECT. (CIELO, 2015)

\subsubsection{Oportunismo}

Oportunismo, por sua vez, "relaciona-se ao padrão de orientação que o indivíduo estabelece para a busca do seu próprio interesse e que termina por se refletir no padrão de relacionamento entre os agentes econômicos" (FERREIRA et al., 2005, p. 07). Ainda sobre o tema, mas nas palavras de Zylbersztajn, lê-se: "o conceito de oportunismo traz à tona uma conotação ética comportamental dos indivíduos, que na base da teoria dos custos de transação, apenas assume que os indivíduos podem agir de modo oportunístico" (ZYLBERSZTAJN, 1995, p. 18); ou seja, os indivíduos podem agir, mas não necessariamente agem. Contudo, se ao menos um indivíduo é capaz de agir oportunisticamente, já é motivo suficiente para a necessidade de monitoramento dos contratos. Mas, como é fácil deduzir, o monitoramento necessário, obrigatoriamente implica em um acréscimo de valor ao custo da operação.

Tendo em vista que o monitoramento ou a inclusão de salvaguardas contratuais não acontece com isenção de custos, os pressupostos comportamentais que foram apresentados estão fortemente relacionados a tais custos (ZYLBERSZTAJN, 1995). A existência do comportamento oportunista interfere nos quesitos confiança e reputação elevando os custos de transação. Em face disso, é possível entender que uma menor propensão ao comportamento oportunista traz uma melhora significativa para o estabelecimento de relações de confiança e aumento da reputação. Por esta razão, é indispensável investigar o grau de propensão a práticas oportunistas em uma organização. Em virtude deste entendimento, pode-se dizer que os dois pressupostos comportamentais (racionalidade limitada e oportunismo) são fundamentais para compreender as diferenças de custos de transação referentes às relações contratuais (FERREIRA; WAQUIL; GONÇALVES, 2006).

\subsubsection{Especificidade dos ativos}

A especificidade dos ativos está relacionada aos ativos específicos de uma transação, ou seja, trata-se de produtos ou serviços que possuem características tão específicas que atendem apenas transações exclusivas. Neste sentido, entende-se que a especificidade dos ativos torna escassa a oferta de produtos e também diminui a demanda, em decorrência de suas características peculiares (MARAGNO; KALATZIS; PAULILLO, 2006). 
Os ativos são considerados específicos quando o retorno relacionado a eles está sujeito à ininterrupção de uma transação específica. Quanto maior a especificidade de um ativo, maiores são os danos decorrentes de práticas oportunistas e, portanto, mais expressivos se tornam os custos de transação (AZEVEDO, 2000). Isto acontece pela falta de alternativas de substituição do bem no mercado, ficando o agente contratante da operação numa relação de dependência em relação ao que fornece.

\subsubsection{Frequência}

No que concerne ao aspecto da Frequência, Ferreira e colaboradores explicam que ela “está relacionada com a recorrência e/ou regularidade de uma transação [uma vez que a] repetição de uma mesma espécie de transação é um dos elementos relevantes para a escolha da estrutura de governança adequada a essa transação" (FERREIRA et al., 2005, p. 08). A frequência é uma forma de medir a recorrência com que uma transação acontece. Quanto maior a frequência, menores serão os custos relacionados à coleta de informações e à elaboração de um contrato mais completo que considere em suas cláusulas restrições ao comportamento oportunista. Além disso, se a frequência for alta, os agentes procurarão não gerar perdas à outra parte, levando em conta que uma prática oportunista pode implicar na interrupção da transação e consequente prejuízo. Sendo assim, em transações recorrentes há o desenvolvimento de reputação e o estabelecimento de uma relação de confiança, o que afasta o interesse dos agentes em colocar em prática um comportamento oportunista visando obter vantagens no curto prazo (AZEVEDO, 2000).

\subsubsection{Incerteza}

A incerteza associada à transação é um fator importante que a caracteriza, influenciando a forma pela qual os resíduos são distribuídos entre os participantes da transação. Este fator, adicionado à probabilidade de ocorrência de práticas oportunistas gera o aumento dos custos de transação, motivando a busca por estruturas alternativas de governança (ZYLBERSZTAJN, 1995). Em um ambiente incerto, os agentes são incapazes de prever o que acontecerá no futuro, sendo assim há uma abertura para que aconteça a renegociação e consequentemente aumenta a probabilidade de problemas advindos de práticas oportunistas (AZEVEDO, 2000). Além disso, na incerteza não existem subsídios que permitam calculá-la ou antecipá-la, pois não há como criar normas para replicar o passado. Insto gera dificuldades 
no sentido de agir com racionalidade frente ao futuro, pois os agentes criam expectativas de longo prazo pautadas num estado de confiança que é subjetivo e volátil (BREITENBACH; BRANDÃO; SOUZA, 2009).

\section{METODOLOGIA}

A presente pesquisa é descritiva, pois "descreve as características de determinada população ou fenômeno, ou o estabelecimento de relações entre variáveis. Sua principal característica está na utilização de técnicas padronizadas de coleta de dados" (VERGARA, 2016, p. 49).

Quanto ao universo pesquisado, trata-se da Universidade Tecnológica Federal do Paraná (UTFPR), mais especificamente o Câmpus Curitiba, que é foco deste estudo por ser o primeiro e maior Câmpus da Universidade e, consequentemente, o que realiza o maior número de pregões, além de consumir o maior orçamento destinado ao funcionamento da instituição. Foram enviados, no período de maio a julho 2019, 1.035 (hum mil e trinta e cinco) e-mails às empresas que participaram, no ano de 2018, de pregões eletrônicos realizados pelo Câmpus Curitiba da UTFPR. O conteúdo do e-mail comtemplava um convite para participação da pesquisa e um link para que as empresas pudessem acessar o questionário na plataforma do Google Forms. Dos questionários enviados, obteve-se o retorno de 89 (oitenta e nove) formulários respondidos, o que traz uma taxa de retorno aproximada de 8,6\%.

O questionário utilizado no presente estudo foi criado e aplicado por Faria (2009) no estudo desenvolvido por ele e reaplicado por Santos (2010) em sua pesquisa. As perguntas do instrumento foram elaboradas à luz da Nova Economia Institucional a fim de se atingir os objetivos propostos. O instrumento aplicado foi estruturado em cinco seções. A seção 4 do questionário foi composta por perguntas do tipo escala Likert e estas questões foram base para a elaboração de constructos alinhados aos princípios da Economia dos Custos de Transação. O quesito racionalidade limitada foi analisado isoladamente por meio de questões dicotômicas (concordo e discordo) com objetivo de averiguar o conhecimento dos fornecedores a respeito da modalidade pregão eletrônico.

Para tratar o banco de dados obtido através da pesquisa foi usada a abordagem quantitativa que é um método de pesquisa social que usa técnicas estatísticas e pressupõe que tudo pode ser quantificado possibilitando traduzir em números as informações a fim de se fazer sua classificação e análise. O uso deste tipo de abordagem possibilita gerar resultados 
que contribuem ao planejamento de ações coletivas e são passíveis de generalização (TRIGUEIRO et al., 2014).

Para realizar o tratamento estatístico foi utilizado o software Statistical Package for the Social Science - SPSS, versão 23.0. Optou-se pelo uso deste software a fim de se analisar as variáveis da mesma forma que os estudos anteriores, o que possibilita fazer o comparativo entre os resultados posteriormente. Os dados foram submetidos a análises multivariadas adotando os mesmos procedimentos realizados por Faria (2009) e Santos (2010).

Para verificar a confiabilidade do questionário em relação aos constructos foi empregado o coeficiente Alfa de Cronbach que conforme nos ensinam Freitas e Rodrigues (2005, p. 1) “é um dos procedimentos estatísticos mais utilizados para mensuração da consistência interna". Ainda, de acordo com os autores é possível considerar como satisfatórios os questionários que apresentem um coeficiente maior que 0,60.

No que tange ao tamanho da amostra obtida, Hair Jr. e colaboradores (2005) explicam que uma amostra com número inferior a 50 (cinquenta) observações dificilmente estará apta à análise fatorial. Os autores também indicam como regra geral ter pelo menos cinco vezes mais observações do que o número de variáveis a serem analisadas. A amostra obteve o número total de 89 (oitenta e nove) observações, estando, portanto adequada à análise fatorial. De acordo com Hair Jr. e colaboradores $(2005$, p. 98$)$ "outro modo de determinar a adequação da análise fatorial examina a matriz de correlação inteira. $\mathrm{O}$ teste Bartlett de esfericidade fornece a probabilidade estatística de que a matriz de correlação tenha correlações significantes entre pelos menos algumas das variáveis". O resultado do teste de esfericidade de Bartlett para a amostra coletada mostrou que a matriz de correlação não é uma matriz identidade $\left(\mathrm{X}^{2}=\right.$ 348,301, Sig. 0,000) demonstrando que existe correlação com as outras variáveis.

Outra medida para quantificar o grau de intercorrelações entre as variáveis e a adequação da análise fatorial é a medida de adequação da amostra de Kaiser-Meyer-Olkin (KMO) (HAIR JÚNIOR et al., 2005). Conforme explica Malhotra (2012, p. 479) "valores altos (entre 0,5 e 1,0) indicam que a análise fatorial é apropriada. Valores abaixo de 0,5 indicam que a análise fatorial pode ser inadequada". O resultado deste índice na pesquisa foi 0,575 indicando sua adequação. Sendo assim, ao considerar o tamanho da amostra coletada e os resultados dos testes realizados verificou-se que o presente estudo estava apto a utilizar a análise fatorial. 
A análise fatorial é o nome dado à metodologia empregada na redução e resumo de dados (MALHOTRA, 2012). O principal objetivo análise fatorial é reduzir uma grande quantidade de variáveis observadas em um número menor de fatores (FIGUEIREDO FILHO; SILVA JUNIOR, 2010).

A análise de cluster é um método utilizado para classificar objetos ou casos em grupos homogêneos denominados clusters (ou conglomerados). A tendência é que os objetos de cada cluster sejam semelhantes entre si e diferentes de objetos de outros grupos (MALHOTRA, 2012). Conforme explica Valli (2012, p. 78), “o objetivo básico da análise de cluster é encontrar os agrupamentos naturais de indivíduos. Um agrupamento de indivíduos devidamente caracterizados pode formar uma população completa ou pode ser uma amostra de alguma população maior". No entendimento de Faria (2009, p. 38) "é possível segmentar os fornecedores da União em função das suas características descritas pela ECT, elucidando assim o grau de risco de cada grupo".

No que se refere à escolha de um procedimento de aglomeração, eles podem ser hierárquicos, não hierárquicos ou de outras formas. O presente estudo utilizou, como procedimento de aglomeração, o método hierárquico aglomerativo de Ward que, segundo Ferreira e Braga, pode ser descrito da seguinte maneira: "O procedimento básico consiste em computar uma matriz de distância ou similaridade entre os indivíduos, a partir da qual se inicia um processo de sucessivas fusões dos mesmos, com base na proximidade ou similaridade entre eles" (FERREIRA; BRAGA, 2007, p. 306). Assim, foi possível dividir em grupos os fornecedores da UTFPR em função das suas características descritas pela ECT.

\section{ANÁLISE DE DADOS E RESULTADOS}

\subsection{PERFIL DOS FORNECEDORES}

Para traçar o perfil dos fornecedores que participam dos processos licitatórios realizados pelo Câmpus Curitiba da UTFPR, mais especificamente aqueles realizados por meio de pregões eletrônicos foram analisadas as seguintes variáveis categóricas levando em consideração os resultados gerais da pesquisa: tempo de existência; número de colaboradores; localização; classificação fiscal; faturamento médio anual; percentual de vitórias alcançadas nas disputas por meio de pregões eletrônicos; parcela do faturamento oriunda de vendas a órgãos públicos; abrangência espacial da participação da empresa em licitações. 
Após avaliar o resultado de todas as questões que objetivaram caracterizar a amostra estudada tem-se condições de traçar o perfil dos fornecedores que participam de licitações através de pregões eletrônicos do Câmpus Curitiba da UTFPR. As principais características são: possuem em média 14 anos de existência, 54 funcionários, estão enquadradas como ME e EPP, são optantes do Simples Nacional, estão localizadas na região Sul do país, já alcançaram sucesso em pelo menos $25 \%$ dos certames que participaram, possuem parcela do faturamento advinda de vendas a órgãos públicos acima de $70 \%$ e participam de licitações em todo o território nacional.

\subsection{RELEVÂNCIA DOS FATORES}

Para avaliar os fatores que os participantes dos processos licitatórios consideram mais importantes foram utilizados constructos de acordo com a Economia dos Custos de Transação. Para analisar a confiabilidade destes constructos foi calculado o Alfa de Cronbach de cada categoria. De acordo com Castro e colaboradores (CASTRO et al., 2016, p. 695), "o coeficiente alfa de Cronbach é um exemplo de teste se utiliza de um fator para expressar o grau de confiabilidade de respostas para um questionário especifico". Para Hair e colaboradores $(2005$, p. 90) o coeficiente é uma "medida de confiabilidade que varia de 0 a 1 , sendo os valores de 0,60 a 0,70 considerados o limite inferior de aceitabilidade". Na tabela 1 verificamos o resultado do teste para os constructos analisados no presente estudo:

Tabela 1 Teste Alfa de Cronbach para as categorias consideradas na pesquisa

\begin{tabular}{lcc}
\hline \multicolumn{1}{c}{ Categoria } & Grupo de Perguntas & Alfa de Cronbach \\
\hline Especificidade dos Ativos & $1,2,4$ & 0,728 \\
Oportunismo & $5,7,8,9$ & 0,733 \\
Incerteza & 10 a 13 & 0,658 \\
Frequência & 14 a 16 & 0,645 \\
\hline
\end{tabular}

Fonte: Dados da pesquisa.

Dos resultados do teste verificados na tabela 1, constatou-se que os valores calculados se encontram acima do limite inferior de aceitabilidade, o que confirma a confiabilidade dos constructos analisados. Aqui vale explicar que as questões 3 e 17 que faziam parte das categorias especificidade dos ativos e frequência respectivamente foram excluídas dos grupos, pois a presença delas fazia com que o valor do coeficiente ficasse muito próximo ou abaixo do limite inferior de aceitabilidade. 
Conforme apresentado no item 3, as variáveis utilizadas demonstraram estar apropriadas à Análise Fatorial, o que foi evidenciado com o resultado do teste de esfericidade de Bartlett que confirmou a existência de correlação com as outras variáveis e com o resultado da medida de adequação da amostra de Kaiser-Meyer-Olkin (KMO) que retornou o valou de 0,575 . Os valores extraídos por meio destes dois destes ratificam a adequação da amostra.

A determinação do número de fatores foi realizada por meio da porcentagem de variância explicada. De acordo com Malhotra (2012, p. 484) "nesta abordagem, determina-se o número de fatores extraídos de forma que a porcentagem acumulada da variância extraída pelos fatores atinja um número satisfatório". Na área de ciências sociais considera-se satisfatória uma solução que explique pelo menos $60 \%$ da variância total (Hair Júnior. et al., 2005). Desta forma foram extraídos cinco fatores com raiz característica superior a 1 e que explicam $61,63 \%$ da variância total.

Assim como nos estudos de Faria (2009) e Santos (2010), em função da análise das cargas fatoriais correspondentes aos coeficientes de correlação, após rotação ortogonal pelo método Varimax foi possível classificar cinco fatores e defini-los de acordo com sua representação homogênea, conforme podemos verificar na tabela 2. A rotação é considerada ortogonal quando os eixos são mantidos em ângulo reto. O procedimento Varimax é um método ortogonal de rotação de fatores que minimiza o número de variáveis com altas cargas em um fator, possibilitando melhor interpretabilidade dos fatores (MALHOTRA, 2012).

Tabela 2 Matriz Fatorial após Rotação Ortogonal Varimax

VARIÁVEIS

Cotação de produtos de má qualidade.

Oportunismo em regiões distantes para compensar custos.

Oportunismo em editais com especificações incompletas.

Cotação de produtos fora das especificações do edital.

\section{FATORES RELACIONADOS}

Fator 1 Fator 2 Fator 3 Fator 4 Fator 5

0,808

0,780

0,697

0,587
Poucos fabricantes do produto vendido.

0,853

Intensidade de concorrência.

0,824

Pequeno número de participantes em Pregões

Eletrônicos.
0,738 
VARIÁVEIS

FATORES RELACIONADOS

Fator 1 Fator 2 Fator 3 Fator 4 Fator 5

Ocorrência de descumprimento de contrato por problemas com acidentes, mau tempo, dentre outros.

Ocorrência de descumprimento de contrato por problemas na contratação de frete.

Ocorrências de descumprimento de contrato por que fornecedores não conseguiram honrar com o compromisso.

Ocorrências de descumprimento de contrato por causa de fatores macroeconômicos.

Esforço para vencer disputas de órgãos públicos conhecidos.

0,823 públicos conhecidos.

Políticas de qualidade mais favoráveis a órgãos públicos conhecidos.

Ocorrência de licitações desertas. 0,732

Esforço para cumprimento das normas. 0,671

Fonte: Dados da Pesquisa

A partir dos resultados extraídos da Tabela 2 é possível observar, por ordem de relevância, os fatores que os fornecedores que participam dos pregões eletrônicos da unidade pesquisada consideram mais importantes neste tipo de certame. Verificou-se que o fator que possui maior peso é o 1) oportunismo seguido pela 2) especificidade dos ativos, 3) incerteza e por último tem-se a 4) frequência. Este resultado se assemelha do encontrado por Faria (2009) em seu estudo realizado na Universidade Federal de Viçosa (UFV). Já o estudo realizado por Santos (2010) na Universidade Federal do Vale do São Francisco (UNIVASF) trouxe um resultado diferente conforme é possível observar na tabela 3.

Tabela 3 Comparativo relativo à variância explicativa dos fatores de risco em licitações

\begin{tabular}{cccc}
\hline Fator & $\begin{array}{c}\text { UTFPR } \\
(\mathbf{2 0 1 9 )}\end{array}$ & $\begin{array}{c}\text { UNIVASF } \\
(\mathbf{2 0 1 0 )}\end{array}$ & $\begin{array}{c}\text { UFV } \\
(\mathbf{2 0 0 9})\end{array}$ \\
\hline Oportunismo & $17 \%\left(1^{\circ}\right)$ & $14 \%\left(2^{\circ}\right)$ & $17 \%\left(1^{\circ}\right)$ \\
Especificidade dos ativos & $15 \%\left(2^{\circ}\right)$ & $12 \%\left(3^{\circ}\right)$ & $14 \%\left(2^{\circ}\right)$ \\
\hline Incerteza & $13 \%\left(3^{\circ}\right)$ & $17 \%\left(1^{\circ}\right)$ & $11 \%\left(3^{\circ}\right)$ \\
Frequência & $10 \%\left(4^{\circ}\right)$ & $09 \%\left(4^{\circ}\right)$ & $10 \%\left(4^{\circ}\right)$ \\
\hline
\end{tabular}

Fonte: Dados da pesquisa, Santos (2010) e Faria (2009). 
A seguir comenta-se um pouco sobre cada fator que os fornecedores que participam dos pregões eletrônicos do Câmpus Curitiba da UTFPR consideram relevantes à luz da Nova Economia Institucional e da Economia dos Custos de Transação.

\subsubsection{Fator 1 - Oportunismo}

O oportunismo foi o fator que teve mais peso na avaliação dos fornecedores do Câmpus Curitiba da UTFPR, o que demonstra existir lacunas na fase de elaboração dos editais, especificação dos materiais ou serviços e até mesmo nas cláusulas contratuais.

O oportunismo pode ocorrer tanto antes do contrato (ex-ante) quanto após o contrato (ex-post) (MARTINS et al., 2017). É o segundo pressuposto comportamental dentro da ECT e dele decorre a incerteza comportamental na avaliação do comportamento de outros agentes ligados à transação (SIMIONI; PEREIRA, 2004). Desta maneira, é necessário que os agentes envolvidos em todos os processos de compra estejam atentos na hora de elaborar os editais e fazer as especificações corretas dos materiais a serem adquiridos ou serviços a serem contratados. É imprescindível fazer um planejamento interno a fim de se preparar os editais da forma mais completa possível para evitar o surgimento de práticas oportunistas. Conforme explica Santos (2010), é difícil alcançar um edital totalmente completo em função das limitações cognitivas dos agentes econômicos, porém quanto mais próximo este instrumento estiver da completude, menor tende a ser a incidência do comportamento oportunista.

Conforme nos explica Santos (2010) tanto a lei de licitações como a lei específica dos pregões preveem severas punições aos que descumprem os contratos. Neste sentido, Zylbersztajn (2002, p. 133) afirma que "o risco de quebras contratuais oportunísticas será controlado à medida que os agentes percebam o risco de punições”. Sendo assim, é essencial que a Administração Pública efetive essas sanções quando da ocorrência de descumprimento às cláusulas contratuais. A aplicação das devidas punições aliada à elaboração de contratos e editais mais completos tende a diminuir a incidência de práticas oportunistas, e consequentemente os custos de transação advindos deste pressuposto comportamental são minimizados.

\subsubsection{Fator 2 - Especificidade dos ativos}

O fator especificidade dos ativos visa medir o quanto os ativos necessários à instituição são específicos, em outras palavras, esta dimensão busca avaliar a gama de opções 
de um determinado bem dentro do mercado. Quanto mais específico for um ativo, menos opções terão no mercado e cria-se, portanto, uma relação de dependência em relação aos fornecedores daquele bem. Conforme explica Zylbersztajn (1995, p. 24) "esta variável implica na existência de custos associados à impossibilidade de utilização alternativa do determinado ativo".

Para Richetti e Santos (2000, p. 36) a "especificidade dos ativos corresponde ao mais importante indutor da forma de governança, uma vez que ativos mais específicos estão associados a formas de dependência bilaterais que irão implicar a estruturação de formas organizacionais". Essa dependência traz riscos para a administração pública e aumenta os custos de transação. Uma vez que há poucas opções de um ativo no mercado, os processos licitatórios se tornam mais complexos e o poder de barganha do órgão público diminui drasticamente.

O surgimento deste fator como o segundo mais importante para os fornecedores do Câmpus Curitiba, revela que os ativos específicos têm papel relevante nas contratações realizadas gerando desta forma uma relação de dependência com estes fornecedores. Sendo assim, é imprescindível que a Universidade identifique melhor as suas demandas previamente e avalie a real necessidade de contratação de bens tão específicos a fim de se diminuir os riscos o os custos que são gerados através de compras de bens com esta característica.

\subsubsection{Fator 3 - Incerteza}

O terceiro fator busca medir o quanto a Administração Pública está exposta a eventos incertos. Um ambiente incerto pode trazer consequências em grande escala à medida que as situações que podem ocorrer durante as transações não podem ser calculadas previamente. Dada a complexidade de identificação de informações por parte dos envolvidos numa transação, quanto maior o nível de incerteza, maiores serão os custos de transação e estes são diretamente proporcionais à assimetria de informações entre as partes (MARTINS et al., 2017). De acordo com Santos (2010) fica evidente, na modalidade pregão eletrônico, a assimetria de informações, pois quem está contratando não tem o conhecimento detalhado que o fornecedor possui do bem licitado e o licitante também não detém o mesmo conhecimento que os pregoeiros possuem de cada etapa interna do certame. Sendo assim, mais uma vez é importante frisar que é necessário elaborar editais da maneira mais completa possível a fim de minimizar os impactos trazidos pela assimetria informacional. 
Além dos editais, é imprescindível, como já dito, redigir as cláusulas contratuais evitando brechas, pois conforme explica Vinholis (1999) quanto maior o nível de incerteza, maiores as lacunas nos contratos e consequentemente há mais possibilidade de acontecerem práticas oportunistas, o que resulta na elevação dos custos de transação.

Neste sentido, é importante destacar que por mais que os eventos incertos de uma transação sejam imprevisíveis, a Administração Pública pode trabalhar preventivamente para minimizar o impacto do fator incerteza. A elaboração dos editais e contratos deve ser realizada de forma minuciosa a fim de que se consiga diminuir as lacunas.

\subsubsection{Fator 4 - Frequência}

O fator frequência mede o quanto uma transação se repete. De acordo com Vinholis (1999, p. 191) “uma transação específica ou de natureza similar que é repetida frequentemente pode levar a desenvolver a reputação". A análise do quesito frequência acontece de forma concomitante à especificidade dos ativos, pois ao lado da variável incerteza, essas três categorias são chamadas de atributos das transações conforme explicado anteriormente. Ao criar uma relação entre níveis de investimentos específicos com padrões de frequência nas transações, têm-se condições estabelecer uma estrutura de governança capaz de reduzir os custos de transação. (FERREIRA et al., 2005). Sendo assim, entende-se que o fator frequência é um dos que têm influência direta sobre os custos de transação. À medida que se aumentam os níveis de recorrência de uma transação é possível criar uma reputação e desenvolver uma relação de confiança que inevitavelmente reduzirão os custos transacionais.

\subsubsection{Racionalidade limitada}

O fator racionalidade limitada foi analisado separadamente dos demais não sendo utilizada a Análise Fatorial para avaliar este quesito. Tendo em vista sua subjetividade, foi feita uma mensuração do grau de racionalidade de cada respondente através da aplicação de doze questões dicotômicas (concordo e discordo) com objetivo de averiguar o conhecimento deles a respeito da modalidade pregão eletrônico. Assim como no estudo de Santos (2010), as respostas foram agrupadas e foi calculado o percentual de acerto da amostra.

Conforme já havíamos mencionado, a racionalidade limitada e a assimetria de informações, presentes na relação entre contratante e fornecedor, acabam abrindo espaço para 
práticas oportunistas. Quanto maior a assimetria, mais limitada é a racionalidade e mais exposta a riscos e comportamentos oportunistas fica a Administração Pública.

O questionário aplicado trazia questões a respeito da modalidade pregão eletrônico e os respondentes deviam dizer se concordavam ou discordavam de cada assertiva apresentada. Desta forma, o grau de racionalidade dos fornecedores do Câmpus Curitiba foi medido através dessas perguntas que avaliaram o conhecimento deles sobre diversos aspectos da modalidade em questão. $\mathrm{O}$ resultado mostrou que a maior parte da amostra se concentrou nos conceitos Insatisfatório e Razoável (94\%), revelando que há uma grande limitação de racionalidade por parte dos fornecedores que contratam com a UTFPR.

\subsection{CLASSIFICAÇÃO DOS FORNECEDORES A PARTIR DOS FATORES DE RISCO}

Para classificar os fornecedores em grupos homogêneos de acordo com as características descritas pela ECT foi realizada uma análise de cluster utilizando o método de Ward e diferentemente dos estudos anteriores, o comportamento das variáveis possibilitou dividir os fatores em dois grupos: Baixo Risco (61\%) e Alto Risco (39\%). Vale ressaltar que durante o procedimento da análise de cluster foram feitas tentativas de agrupamento em três conglomerados, porém à medida que se dividia em um número maior de clusters apareceriam inconsistências teóricas e a melhor configuração para o presente estudo foi a de dois grupos distintos, pois com esse número manteve-se a consistência teórica.

O resultado observado se mostra totalmente diverso dos estudos anteriores, essa discrepância pode ter explicação tanto no fato de que na UTFPR conseguiu-se dividir os fornecedores em dois grupos extremos (alto e baixo risco) como no fato de que os estudos foram realizados em regiões diferentes e em épocas distintas, tendo em vista que o lapso temporal é de aproximadamente dez anos entre a pesquisa atual e as que embasaram este trabalho. A Tabela 4 traz o resultado comparativo por estudo:

Tabela 4 Distribuição dos fornecedores em grupos de riscos

\begin{tabular}{cccc}
\hline Grupo & $\begin{array}{c}\text { UTFPR } \\
(\mathbf{2 0 1 9 )}\end{array}$ & $\begin{array}{c}\text { UNIVASF } \\
\mathbf{( 2 0 1 0 )}\end{array}$ & $\begin{array}{c}\text { UFV } \\
(\mathbf{2 0 0 9 )}\end{array}$ \\
\hline Baixo Risco & $61 \%$ & $14 \%$ & $18 \%$ \\
Risco Moderado & - & $83 \%$ & $32 \%$ \\
Alto Risco & $39 \%$ & $03 \%$ & $50 \%$ \\
\hline
\end{tabular}

Fonte: Dados da pesquisa, Santos (2010) e Faria (2009). 


\section{MENSURAÇÃO DO GRAU DE RISCO NOS PROCESSOS LICITATÓRIOS DE UMA INSTITUIÇÃO \\ DOI: https://doi.org/10.5007/1983-4535.2021.e73528}

A tabela 5 foi obtida através do cruzamento de dados oriundos da seção de perfil dos fornecedores com a distribuição por grupos de risco. O objetivo do cruzamento dessas informações foi verificar a relação entre a maturidade da empresa, seu faturamento, a participação das contratações com órgãos públicos nas receitas da empresa e a frequência com que vence licitações com a sua segmentação nos grupos de risco.

Tabela 5 Variáveis descritivas

\begin{tabular}{l|c|c|c|c|c}
\multicolumn{1}{c|}{ Variáveis } & Grupos & Mínimo & Máximo & Média & Desvio Padrão \\
\hline Tempo de & Baixo Risco & 2 & 50 & 15,33 & 11,21 \\
Existência (anos) & Alto Risco & 2 & 32 & 9,94 & 8,34 \\
\hline Faturamento & Baixo Risco & $180.000,00$ & $228.000 .000,00$ & $12.939 .166,67$ & $37.664 .415,39$ \\
anual (R\$) & Alto Risco & $65.000,00$ & $34.000 .000,00$ & $3.479 .117,65$ & $7.564 .364,33$ \\
\hline $\begin{array}{l}\text { Participação das } \\
\text { licitações no }\end{array}$ & Baixo Risco & 10 & 100 & 69,42 & 29,51 \\
faturamento (\%) & Alto Risco & 0 & 100 & 61,44 & 35,64 \\
\hline $\begin{array}{l}\text { Percentual de } \\
\text { disputas } \\
\text { vencidas }\end{array}$ & Baixo Risco & 1 & 85 & 30,71 & 24,60 \\
\end{tabular}

Fonte: Dados da pesquisa.

\subsubsection{Grupo 1 - Baixo Risco}

É formado por $61 \%$ das empresas e possui os menores índices de oportunismo e especificidade dos ativos e incerteza. Em relação à frequência, esta variável é superior ao outro grupo revelando que há uma relação de confiança com os fornecedores pertencentes a este grupo, ou seja, ao contratar com empresas que possuem o perfil de baixo risco a universidade está exposta a uma gama menor de eventos incertos.

Os menores índices nos fatores especificidade dos ativos e oportunismo aliado ao maior índice no quesito frequência gera a redução da incerteza em todo o processo, o que diminui os custos de transação.

Sobre as características encontradas na tabela 5, destaca-se a maturidade, são empresas com tempo maior de existência e também possuem faturamento maior, o que pode de certo modo explicar as menores médias nas variáveis que afetam negativamente os custos de transação. Empresas mais antigas no mercado tendem a ser mais consolidadas e prezando por sua tradição e reputação possuem um comportamento mais ético e profissional, trazendo uma segurança na hora de fazer as transações. 


\subsubsection{Grupo 2 - Alto Risco}

Este grupo é formado pelos outros 39\% dos fornecedores do Câmpus Curitiba da UTFPR. Apresenta as maiores médias nos itens: especificidade dos ativos, oportunismo e incerteza e menor índice em relação à frequência. A configuração dos fatores deste grupo faz com que ele represente um grande risco para a universidade.

Diante do exposto, vale lembrar que é primordial a aplicação de sanções quando da ocorrência de quebras contratuais, bem como a elaboração minuciosa de contratos e editais buscando sua forma mais completa a fim de afastar práticas oportunistas. Também é importante ressaltar a necessidade de elaborar editais e contratos da maneira mais próxima da completude a fim de minimizar os impactos trazidos pelo fator incerteza.

Sobre as características encontradas na tabela 5, verifica-se que este grupo é formado por empresas que possuem menos tempo de existência e também menor faturamento. Estes dados demonstram que este grupo é menos consolidado no mercado em comparação ao grupo de baixo risco, o que inevitavelmente traz mais riscos às transações, pois contratar com empresas com pouca maturidade traz uma insegurança maior. Outro fator que merece atenção é o fato destas empresas terem um percentual maior de vitórias em licitações por pregão eletrônico, ou seja, este dado pode evidenciar que este grupo acaba sendo vitorioso por praticar preços menores, porém às vezes isto não garante nada para a administração, muito pelo contrário, preços muito abaixo do valor de mercado podem gerar problemas futuros como entrega de produtos de baixa qualidade ou fora das especificações.

Apesar deste grupo ser composto por menos empresas que o grupo de baixo risco e representar um percentual menor do total da amostra, deve-se atentar para o fato de que mesmo sendo mais baixo, o percentual que representa o grupo é de quase $40 \%$ do total, ou seja, pode-se concluir que o Câmpus Curitiba da UTFPR está exposto a riscos potenciais quando da contratação através da modalidade pregão eletrônico.

\section{CONSIDERAÇÕES FINAIS}

Os resultados da pesquisa possibilitaram caracterizar a amostra estudada e verificou-se que os fornecedores do Câmpus Curitiba da UTFPR têm as seguintes características: possuem em média 14 anos de existência, 54 funcionários, estão enquadradas como ME e EPP, são optantes do Simples Nacional, estão localizadas na região Sul do país, já alcançaram sucesso em pelo menos $25 \%$ dos certames que participaram, possuem parcela do faturamento advinda 
de vendas a órgãos públicos acima de $70 \%$ e participam de licitações em todo o território nacional.

As análises seguintes permitiram averiguar os fatores que os participantes dos processos licitatórios consideram mais relevantes no certame de acordo com os princípios da Economia dos Custos de Transação. Foi verificado que o fator que possui maior peso é o oportunismo seguido pela especificidade dos ativos, incerteza e por último ficou a frequência, considerada o fator menos importante na visão das empresas que contratam com o Câmpus Curitiba da UTFPR. O grau de racionalidade foi analisado de forma isolada e mostrou que $94 \%$ dos fornecedores possuem conhecimento regular a insatisfatório referente à modalidade Pregão Eletrônico.

Posteriormente foi possível classificar os fornecedores do Câmpus Curitiba da Universidade Tecnológica Federal do Paraná em dois grupos distintos. O grupo de baixo risco apresentou o maior percentual, sendo formado por $61 \%$ das empresas e o grupo de alto risco foi formado pelos outros 39\% dos fornecedores do Câmpus Curitiba da UTFPR. Apesar deste grupo ser composto por menos empresas que o grupo de baixo risco e representar um percentual menor do total da amostra, é necessário atentar para o fato de que mesmo sendo mais baixo, o percentual que representa o grupo é de quase $40 \%$ do total, ou seja, o Câmpus Curitiba da UTFPR está exposto a riscos potenciais quando da contratação através da modalidade pregão eletrônico.

A partir dos resultados encontrados é possível fornecer à UTFPR uma visão a respeito desse processo tão relevante para a Universidade e conforme foi demonstrado na pesquisa, há diversos fatores que implicam em riscos, incertezas e custos de transação neste tipo de relação entre fornecedores e a instituição. A ordem de relevância dos fatores encontrada na pesquisa nos traz informações preciosas que devem ser analisadas com cautela a fim de se criar procedimentos mais rigorosos na hora de elaborar editais, redigir contratos, bem como fazer com que se cumpra de forma mais severa as punições que devem ser aplicadas por ocasião do descumprimento de contratos.

O fato de a Universidade estar exposta a atitudes oportunistas, ter como segundo fator mais importante a especificidade dos ativos e logo em seguida a incerteza mostra que há muitas melhorias a serem implantadas em todo o processo a fim de se minimizar o impacto destes fatores. Em tempos de contingenciamento, reduzir os custos de transação é 
imprescindível para que se consiga continuar prezando pelo funcionamento da instituição de forma satisfatória.

\section{REFERÊNCIAS BIBLIOGRÁFICAS}

ALVES-ANDRADE, F.; GUARIDO FILHO, E. R.; EBERLE, V. Pregão Eletrônico como Mito Racional: análise dos processos licitatórios do Banco do Brasil. Desenvolvimento em Questão, Ijuí/RS, n. 41, p. 233 - 247, outubro 2017. Disponível em: < $<$ https://www.researchgate.net $>$. Acesso em: 17 nov. 2018.

AZEVEDO, P. F. Nova economia institucional: referencial geral e aplicações para a agricultura. Agric., São Paulo, v. 47, n. 1, p. 33-52, 2000. Disponível em: $<$ http://www.gepai.dep.ufscar.br $>$. Acesso em: 12 set. 2019.

BRASIL. Decreto $n^{0}$ 5.450, de 31 de maio de 2005. Diário Oficial, Brasília/DF, 2005.

BREITENBACH, R.; BRANDÃO, J. B.; SOUZA, R. S. Teorias organizacionais e a Nova Economia Institucional: uma discussão acerca dos elementos constitucionais das organizações. $\mathbf{4 7}^{\circ}$ Congresso da SOBER (Sociedade Brasileira de Economia, Administração e Sociologia Rural), Porto Alegre, julho 2009. Disponível em: $<$ https://sober.org.br>. Acesso em: 29 nov. 2018.

BUENO, N. P. Possíveis contribuições da Nova Economia Institucional à pesquisa em História Econômica Brasileira: uma releitura das três obras clássicas sobre o período colonial. EST. ECON., São Paulo, v. 34, n. 4, p. 777 - 804, outubro-dezembro 2004. Disponível em: $<$ https://www.scielo.br $>$. Acesso em: 28 nov. 2018.

CASTRO, U. R.; PALHA, A. J. P.; MARTINS, J. C. A.; OLIVEIRA, N. R. A confiabilidade de um questionário avaliando as práticas diárias de trabalhadores envolvidos com a saúde mental da comunidade. Acta paul enferm., São Paulo, v. 29, n. 6, p. 693-699, dez. 2016.

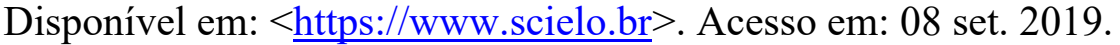

CIELO, I. D. O sistema de integração da avicultura de corte na mesorregião oeste paranaense: uma análise sob a ótica da nova economia institucional. (Tese de doutorado). Toledo/PR: Programa de Pós-Graduação em Desenvolvimento Regional da Universidade Estadual do Oeste do Paraná, 2015.

FARIA, E. R. Desempenho, risco e funcionalidade do pregão eletrônico no setor público. Dissertação de Mestrado: Universidade Federal de Viçosa, 2009.

FARIA, M. A. A.; OLIVEIRA, I. L. M. C. Licitação pública: análise da utilização da modalidade pregão na forma eletrônica - Pregão Eletrônico. Revista Eletrônica de Educação da Faculdade Araguaia, Goiânia, n. 9, p. 349 - 366, 2016. Disponível em: $<$ http://www.fara.edu.br $>$. Acesso em: 28 nov. 2019.

FARINA, E. M. M. Q.; AZEVEDO, P. F.; SAES, M. S. M. Competitividade: mercado, estado e organizações. São Paulo: Editora Singular, 1997. 
FERREIRA, G. M. V; GONÇALVES, W. M.; PEDROZO, E. A.; TAKITANE, I. C. A economia dos custos de transação sob uma análise crítica: perspectivas de aplicação no agronegócio. XLIII Congresso da SOBER: Instituições, Eficiência, Gestão e Contratos no Sistema Agroindustrial, Ribeirão Preto/SP, Julho 2005. Disponível em: $<$ https://www.scribd.com>. Acesso em: 29 nov. 2018.

FERREIRA, G. M. V.; WAQUIL, P. D.; GONÇALVES, W. M. Racionalidade limitada e oportunismo na cadeia do café: impacto nas formas contratuais do consórcio agrícola de fazendas especializadas. Organizações Rurais; Agroindustriais, Lavras/RS, v. 8, n. 3, p. 378-392, 2006. Disponível em: < http://www.spell.org.br>. Acesso em: 15 ago. 2019.

FERREIRA, M. A. M.; BRAGA, M. J. Desempenho das cooperativas na indústria de laticínios do Brasil: uma abordagem por grupos estratégicos. R. Adm., São Paulo, v. 42, n. 3, p. 302-312, jul./ago./set. 2007. Disponível em: $<$ http://conteudo.enap.gov.br $>$. Acesso em: 08 set. 2019.

FIGUEIREDO FILHO, D. B.; SILVA JUNIOR., J. A. Visão além do alcance: uma introdução à análise fatorial. Opinião Pública, Campinas/SP, v. 16, n. 1, p. 160-185, jun. 2010. Disponível em: $<$ https://www.scielo.br $>$. Acesso em: 08 set. 2019.

FREITAS, A. L. P.; RODRIGUES, S. G. A avaliação da confiabilidade de questionários: uma análise utilizando o coeficiente alfa de Cronbach. XII SIMPEP, Bauru/SP, nov. 2005.

Disponível em: <https://www.researchgate.net $>$. Acesso em: 24 ago. 2019.

HAIR JÚNIOR., J. F.; BLACK, W. C.; BABIN, B. J.; ANDERSON, R. E.; TATHAM, R. L. Análise multivariada de dados. Porto Alegre: Bookman, 2005.

MALHOTRA, N. K. Pesquisa de marketing: uma orientação aplicada. Porto Alegre: ARTMED, 2012

MARAGNO, R. C.; KALATZIS, A. E. G.; PAULILLO, L. F. O. A nova economia institucional: aspectos que influenciam na relação comercial Brasil - União Européia. XIII SIMPEP, Bauru/SP, nov. 2006. Disponível em: $<$ https://simpep.feb.unesp.br $>$. Acesso em: 08 ago. 2019.

MARTINS, V. Q.; MARQUEZAN, L. H. F.; DIEHL, C. A.; FLORES, J. S. Alta especificidade de ativos na avaliação dos custos de transação: o caso da Arena do Grêmio. Revista Universo Contábil, Blumenau/SC, v. 13, n. 2, p. 130 - 148, abr./jun. 2017. Disponível em: $<$ https://www.redalyc.org $>$. Acesso em: 27 nov. 2018.

PAZ, S. J. F. A experiência com a utilização do pregão eletrônico nas aquisições de bens o caso de unidade gestoras do Exército Brasileiro sediadas no Estado do Rio de Janeiro. Dissertação de Mestrado (Mestrado Profissional em Administração Pública): Escola Brasileira de Administração Pública e de Empresas da Fundação Getúlio Vargas, 2016. 
PONTES, H. U. N.; XAVIER, A. R. O pregão como processo de compras no governo do Estado do Ceará. Revista Expressão Católica, Quixadá/CE, v. 6, n. 2, p. 63 - 72, jul.-dez. 2017. Disponível em: <https://www.researchgate.net> . Acesso em: 16 nov. 2018.

RICHETTI, A.; SANTOS, A. C. O sistema integrado de produção de frango em corte em Minas Gerais: uma análise sob a ótica da ECT. Revista de Administração da UFLA, Lavras/MG, v. 2, n. 2, Jul./Dez. 2000. Disponível em: $<$ http://revista.dae.ufla.br $>$. Acesso em: 29 nov. 2018.

SANTOS, M. R. Avaliação dos riscos do pregão eletrônico em licitações públicas: um estudo de caso. Trabalho de Conclusão de Curso (Especialização em Gestão em Organizações Públicas): Universidade Federal do Vale do São Francisco, 2010.

SIMIONI, F. S.; PEREIRA, L. B. Sociedade Brasileira de Economia, Administração e Sociologia Rural. Cadeia agroindustrial da maçã: uma análise da estrutura de governança sob a ótica da economia dos custos de transação (palestra), 2004. Disponivel em: $<$ https://sober.org.br>. Acesso em: 01 set. 2019.

TRIGUEIRO, R. M.; RICIERI, M.; FREGONEZE, G. B.; BOTELHO, J. M. Metodologia científica. Londrina/PR: Editora e Distribuidora Educacional S.A., 2014

VALLI, M. Análise de Cluster. Augusto Guzzo Revista Acadêmica, São Paulo, n. 4, p. 77 -

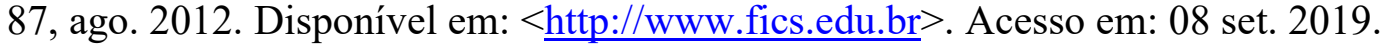

VERGARA, S. C. Projetos e relatórios de pesquisa em administração. São Paulo: Atlas, 2016.

VINHOLIS, M. M. B. Uma análise da aliança mercadológica da carne bovina baseada nos conceitos da Economia dos Custos de Transação. II Workshop Brasileiro de Gestão de Sistemas Agroalimentares, Ribeirão Preto/SP, 1999. Disponível em:

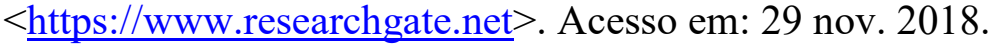

WILLIAMSON, O. E. The economic institutions os capitalism. Nova Iorque: Free Press, 1985.

ZYLBERSZTAJN, D. Estruturas de Governança e Coordenação do Agribusiness: uma aplicação da Nova Economia das Instituições. Tese de Livre Docência: Universidade de São Paulo, 1995.

ZYLBERSZTAJN, D. Organização Ética: um Ensaio sobre Comportamento e Estrutura das Organizações. Rev. adm. contemp., Curitiba, v. 6, n. 2, p. 123-143, mai./ago. 2002.

Disponível em: $<$ https://www.scielo.br $>$. Acesso em 11 set. 2019. 